\title{
Do we have enough evidences that make you safe to treat a man with hypogonadism one year after a radical prostatectomy for prostate cancer? | Opinion: Not Yet
}

\author{
Marcelo Langer Wroclawski ${ }^{1,2}$, Flavio Lobo Heldwein ${ }^{3,4}$ \\ ${ }^{1}$ Hospital Israelita Albert Einstein, São Paulo, SP, Brasil; ${ }^{2}$ Faculdade de Medicina do ABC, Santo André, SP, \\ Brasil ; ${ }^{3}$ Universidade do Sul de Santa Catarina, SC, Brasil; ${ }^{4}$ Universidade Federal de Santa Catarina, SC, Brasil
}

Keywords: Prostatic Neoplasms; Hypogonadism; Prostatectomy; Therapeutics

Prostate cancer (PCa) is a heterogeneous disease. After almost a decade of contradictory screening recommendations made by expert and advisory panels (1), prostate cancer has risen again as the second leading cause of cancer death in American males (2).

PCa is androgen dependent. Research on biological effects of testosterone and its relationship with PCa awarded Butenandt with the Nobel Prize in Chemistry in 1939, and Huggins with The Nobel Prize in Physiology or Medicine in 1966 (3, 4). In 1941, Huggins and Hodges observed that castration could cause a decrease of PCa serum marker activity and that administration of exogenous testosterone propionate resulted in its increase. Indeed, different research groups repeatedly showed that PCa culture cells are stimulated by administration of testosterone and that deprivation induces apoptosis $(5,6)$. These traditional assumptions are the base of metastatic PCa treatment until nowadays.

Similarly to prostate cancer, testosterone-deficiency (TD) (previously named late-onset hypogonadism) prevalence increases with aging. Traditionally an underreported condition, the growing interest on testosterone deficiency resulted in an increase in screening of symptomatic middle-age men and subsequently an exponential boost in testosterone prescriptions, up to 4-fold in the last two decades (7-9).

The main goals of testosterone supplementation therapy (TST) are: restore libido, sexual function, cognition, wellbeing, mood and behavior. Thus, in an evidence-based era, aiming to recommend a safe and effective treatment, we should primarily address the following question: What are the evidences to treat any man with age-related hypogonadism?

A gradual annual decline of testosterone production is related with male aging. If low-testosterone is functional along with a normal aging process or, contrarily, it represents a disease pathologically associated with certain medical conditions such as obesity, smoking, stress and metabolic syndrome, is debatable (10-13). However, TD is commonly used to justify testosterone-replacement, particularly in males with a range of unspecific signs and symptoms, generally associated with aging and/or habits.

A literature review regarding TST on age-related low testosterone could be confusing. Recent guidelines and drug safe communications made by US Food and Drug Administration (FDA) and Australian Endocrine Society have raised skepticism concerning TST $(14,15)$. Different definitions of biochemical threshold and methods of assessment, lack of consensus on scre- 
ening and follow-up recommendations, use of different tools to report outcomes even in the same study, low rate of detail reports of study withdrawal, harms and benefits, make medical advice in this field a challenging task.

Another classic example of the controversies that surround testosterone-replacement therapy is its real efficacy. If you are against TST, you are a fan of the recently published systematic review of Huo et al. After reviewing 156 randomized clinical trials, their paper cast doubt on the validity of "low-testosterone" selection of aging male patients who receive TST (16). Even sexual function domains, such as erectile dysfunction and libido, did not find consistent improvements with TST when compared to placebo. The authors concluded that TST is not supported by randomized clinical data. But if you are a TST believer, you will find a solid ground in an abundant amount of papers, such as the RHYME study (17-19). Despite a significant improvement in sexual function measured by IIEF5 questionnaire, the authors acknowledge that this improvement was small, and may have been biased by $25 \%$ of the patients reporting a concomitant use of 5 phosphodiesterase inhibitors (17).

Furthermore, recently published reviews and meta-analysis provide support to the hypothesis that exogenous testosterone increases cardiovascular risks (as high as 54\% increase of CV events) (20), while others concluded that there is no effect (21-24).

Additionally, since RCTs are usually designed to demonstrate benefit or not with a treatment, adequately powered clinical trials for rare outcomes are challenging. Onasanya et al. reviewed the 6 systematic reviews available on TST and suggested that it would require more than 17,000 participants in each trial group to draw a conclusion about more unusual risks (24). The RCTs published to date varied in size ranging from 29 to 406 men (25). Therefore, we should keep in mind that the majority of prospective studies are underpowered to give a categorical answer about uncommon harms. Also, RCTs often include biased populations enrolled using optimized selection criteria, and those inclusion criteria could not reflect our daily practice.
Despite the popularity and initial enthusiasm with the use of testosterone, several authors report a high discontinuation rate (80-85\% after one year) (26). Other critical issue on testosterone-replacement is sponsored trials. In the USA, testosterone therapy sales market rose from an estimated $\$ 2$ billion in 2012, to $\$ 5$ billion by 2017 (26). Regarding TST, Alexander et al. reported that the majority of the RCTs (at least 25 of 39) included in their review were sponsored by pharmaceutical companies (25). Thus, data from sponsored trials must be interpreted accordingly, considering a possible lobby of pharmaceutical industry $(27,28)$.

\section{Testosterone and prostate cancer}

The understanding of the complex biology of prostate cancers is only beginning. However, proponents of TST claim that the growth interest in TST led to a better understanding of the multi-faceted biological relationship between androgens and prostate health and that the conventional wisdom was challenged by the saturation model hypothesis (29). In this model, Morgentaler theorizes that an increased testosterone level above the baseline does not result in further stimulation of prostate cells, because their androgen receptors are fully bound at relatively low serum testosterone concentrations. In vivo, the relationship between circulating levels of testosterone and PSA reaches a saturation point approximately at $251 \mathrm{ng} / \mathrm{dL}(8.7 \mathrm{nmoL} / \mathrm{L})$ $(30,31)$. However, critics declare that this hypothesis could be simplistic and misleading, not recognizing the different clones of tumor cells that constitute the micro-environment of an aggressive PCa. The unique biology of each clone cells may respond differently to an exogenous stimulus of testosterone, exhibiting different androgen receptors affinity and pathways.

Data regarding levels of serum testosterone and development of $\mathrm{PCa}$ are inconclusive. Control arm of the REDUCE trial and population based studies have shown no association between TD and aggressive PCa $(32,33)$. Nevertheless, several studies point to different conclusions, reporting a direct association between TD and high grade $\mathrm{PCa}$ and adverse pathological and clinical features (34-36). In 2005, Teloken et al. 
reported a relationship between baseline low-testosterone and positive surgical margins (37). PCa genesis occurs in an eugonadic age group, around the 30s and 40s. The above reports, although small and retrospective, are consistent with the natural history of $\mathrm{PCa}$, indicating a reverse association between testosterone and prostate cancer, suggesting that when a $\mathrm{PCa}$ develops in a low-testosterone environment, its biological stimulation pathways independent of testosterone make those tumors more aggressive. If this fact proves correct in the future, safety aspects are even more important in TST candidates with PCa history.

The profile of patients undergoing radical prostatectomy has changed. Currently, favorable-risk tumors are been conducted with active surveillance, while intermediate and high-risk $\mathrm{PCa}$ are the majority of patients treated with radical surgery (38). The more aggressive the PCa, the more uncertain is its biological behavior.

Mainly expert opinion publications (39, 40) conclude that testosterone replacement is effective and does not raise the risk of biochemical recurrence (BCR) or the need for adjuvant treatments after radical prostatectomy (RP).

Actually, no prospective clinical trials on TST in surgically treated PCa patients have been published. After reviewing the literature, we identified only six small case series (41-46), including a total of 297 cases of PCa patients submitted to RP and post-operatively treated with TST (Table-1).

These case series vary in size from 7 to 103 men, as well as follow-up duration from 13 to 72 months. Only 84/297 (29\%) had a Gleason $\geq 7$ mentioned. In a retrospective study using Surveillance, Epidemiology, and End Results-Medicare (SEER) database, Kaplan et al. identified 98 post-prostatectomy patients using TST, but no specific stats were provided for those men (45). More recently, Ory et al. reported 22 men treated with RP and subsequently submitted to TST with a mean follow-up of 48 months. No BCRs were registered when adopting the definition of two postop PSA $>0.2 \mu \mathrm{g} / \mathrm{L}$. Nevertheless, the authors noted a statistical significant increase of PSA at 50 months (from undetectable to mean PSA $=0.006 \mu \mathrm{g} / \mathrm{L} ; \mathrm{p}=0.048$ ). The authors induced hypogonadism in six men treated with neoadjuvant androgen deprivation prior to RP. Probably, this is an even more specific subpopulation, and should be studied separately (46).

Available data are still far from being either robust or mature. The short-term follow-up data on TST in men that underwent RP does not contribute to understand the downsides of testosterone replacement in this scenario. Also, we need to point out that the risks may have been diluted when we considered low-risk tumors recruited altogether with more aggressive PCas in these case series.

Table 1 - Results of testosterone-replacement in men submitted to radical prostatectomy.

\begin{tabular}{|c|c|c|c|c|c|c|}
\hline & Study type & $\begin{array}{c}\text { Total } \\
\text { Number of } \\
\text { patients }\end{array}$ & $\begin{array}{l}\text { Intermediate } \\
\text { and high risk } \\
\text { PCa patients }\end{array}$ & $\begin{array}{l}\text { Mean follow- } \\
\text { up (months) }\end{array}$ & BCR & $\begin{array}{l}\text { Mortality or } \\
\text { metastasis }\end{array}$ \\
\hline $\begin{array}{l}\text { Kaufman and } \\
\text { Graydon, } 2004 \text { (41) }\end{array}$ & retrospective & 7 & 1 & 24 & none & - \\
\hline $\begin{array}{l}\text { Agarwal and } \\
\text { Oefelein, } 2005 \text { (42) }\end{array}$ & retrospective & 10 & 8 & 19 & none & - \\
\hline $\begin{array}{l}\text { Khera et al., } 2009 \\
(43)\end{array}$ & retrospective & 57 & 30 & 13 & none & - \\
\hline $\begin{array}{l}\text { Pastuszak et al., } \\
2013(44)\end{array}$ & retrospective & 103 & 26 & 27.5 & 4 & - \\
\hline $\begin{array}{l}\text { Kaplan et al., } 2014 \\
\text { (45) }\end{array}$ & retrospective & $98^{*}$ & NA & 72 & $\begin{array}{l}\text { Not } \\
\text { mentioned }\end{array}$ & No risk \\
\hline $\begin{array}{l}\text { Ory et al., } 2016 \\
(46)\end{array}$ & retrospective & 22 & 19 & 48 & None** & $6^{\star * *}$ \\
\hline
\end{tabular}

BCR = biochemical recurrence; NA - not available;

${ }^{*}=98$ men with $>60$ days of TST duration.

** $=$ Significant increase in PSA at 50 months ( $p=0.048$ )

$* * *=6$ men received neoadjuvant androgen deprivation 


\section{FINAL CONSIDERATIONS}

Low-testosterone could be a normal age-related event or a pathological process associated with certain medical conditions. Contrarily to what proponents of TST believe, neither TST efficacy nor its safety have been undoubtedly proved by an unbiased long-term RCT, even in a healthy population.

There is a complex interaction between testosterone and normal/malignant prostate cells and PCa has distinct androgen stimulation pathways that are still not completely elucidated.

\section{REFERENCES}

1. Wroclawski ML. New US Preventive Service Task Force recommendations for prostate cancer screening: a needed update, but not enough. Einstein (Sao Paulo). 2017;15:7-10.

2. Siegel RL, Miller KD, Jemal A. Cancer statistics, 2018. CA Cancer J Clin. 2018;68:7-30.

3. Shampo MA, Kyle RA, Steensma DP. Adolf Butenandt-Nobel Prize for chemistry. Mayo Clin Proc. 2012;87:e27.

4. Huggins C, Hodges CV. Studies on prostatic cancer: I. The effect of castration, of estrogen and of androgen injection on serum phosphatases in metastatic carcinoma of the prostate. Cancer Res. 1941:1;293-7.

5. Klus GT, Nakamura J, Li JS, Ling YZ, Son C, Kemppainen $\mathrm{JA}$, et al. Growth inhibition of human prostate cells in vitro by novel inhibitors of androgen synthesis. Cancer Res. 1996;56:4956-64.

6. Klotz L. Testosterone therapy and prostate cancer-safety concerns are well founded. Nat Rev Urol. 2015;12:48-54.

7. Baillargeon J, Urban RJ, Kuo YF, Holmes HM, Raji MA, Morgentaler A, et al. Screening and monitoring in men prescribed testosterone therapy in the U.S., 20012010. Public Health Rep. 2015;130:143-52.

8. Gabrielsen JS, Najari BB, Alukal JP, Eisenberg ML. Trends in Testosterone Prescription and Public Health Concerns. Urol Clin North Am. 2016;43:261-71.

9. Yafi FA, Haney NM, Anaissie J, DeLay KJ, Trost L, Khera M, et al. Practice Patterns in the Diagnosis and Management of Hypogonadism: A Survey of Sexual Medicine Society of North America Members. Urology. 2017;106:87-95.

10. Morgentaler A, Khera M, Maggi M, Zitzmann M. Commentary: Who is a candidate for testosterone therapy? A synthesis of international expert opinions. J Sex Med. 2014;11:1636-45.
Until nowadays, only results of small observational retrospective studies evaluating TST in patients treated with radical prostatectomy are available and there is no definitive data that the prescription of TST in this scenario is safe and does not lead to BCR or clinical progression, mainly in an era when more aggressive $\mathrm{PCa}$ are being treated by surgery.

Discussions on TST should start with what we know regarding benefits and risks of this treatment. Categorical statements about TST safety should be evidence-based. At present, clinicians must inform their patients that oncological outcomes of TST on patients after RP are still unknown.

11. Guay AT, Traish A. Testosterone deficiency and risk factors in the metabolic syndrome: implications for erectile dysfunction. Urol Clin North Am. 2011;38:17583.

12. Corona G, Sforza A, Maggi M. Testosterone Replacement Therapy: Long-Term Safety and Efficacy. World J Mens Health. 2017;35:65-76.

13. Sanchez E, Pastuszak AW, Khera M. Erectile dysfunction, metabolic syndrome, and cardiovascular risks: facts and controversies. Transl Androl Urol. 2017;6:28-36.

14. (FDA) UFadA. Testosterone Products: Drug Safety Communication - FDA Cautions About Using Testosterone Products for Low Testosterone Due to Aging; Requires Labeling Change to Inform of Possible Increased Risk of Heart Attack And Stroke2015. Available from: <https://www. fda.gov/Safety/MedWatch/SafetyInformation/ SafetyAlertsforHumanMedicalProducts/ucm436280. htm>

15. Yeap BB, Grossmann M, McLachlan RI, Handelsman DJ, Wittert GA, Conway AJ, et al. Endocrine Society of Australia position statement on male hypogonadism (part 2): treatment and therapeutic considerations. Med J Aust. 2016;205:228-31.

16. Huo $S$, Scialli $A R$, McGarvey $S$, Hill $E$, Tügertimur B, Hogenmiller A, et al. Treatment of Men for "Low Testosterone": A Systematic Review. PloS One. 2016;11:e0162480.

17. Rosen RC, Wu F, Behre HM, Porst H, Meuleman EJH, Maggi M, et al. Quality of Life and Sexual Function Benefits of Long-Term Testosterone Treatment: Longitudinal Results From the Registry of Hypogonadism in Men (RHYME). J Sex Med. 2017; 14:1104-1115. 
18. Maggi M, Wu FC, Jones TH, Jackson G, Behre HM, Hackett $\mathrm{G}$, etal. Testosterone treatment is not associated with increased risk of adverse cardiovascular events: results from the Registry of Hypogonadism in Men (RHYME). Int J Clin Pract. 2016;70):843-52.

19. Corona G, Rastrelli G, Morgentaler A, Sforza A, Mannucci E, Maggi M. Meta-analysis of Results of Testosterone Therapy on Sexual Function Based on International Index of Erectile Function Scores. Eur Urol. 2017;72:1000-11.

20. Xu L, Freeman G, Cowling BJ, Schooling CM. Testosterone therapy and cardiovascular events among men: a systematic review and meta-analysis of placebo-controlled randomized trials. BMC Med. 2013;11:108.

21. Corona G, Dicuio M, Rastrelli G, Sforza A, Maggi M. Testosterone replacement therapy and cardiovascular risk. G Ital Cardiol (Rome). 2017;18:745-53.

22. Calof OM, Singh $A B$, Lee ML, Kenny AM, Urban RJ, Tenover JL, et al. Adverse events associated with testosterone replacement in middle-aged and older men: a meta-analysis of randomized, placebocontrolled trials. J Gerontol A Biol Sci Med Sci. 2005;60:1451-7.

23. Tanna MS, Schwartzbard A, Berger JS, Underberg J, Gianos E, Weintraub HS. Management of Hypogonadism in Cardiovascular Patients: What Are the Implications of Testosterone Therapy on Cardiovascular Morbidity? Urol Clin North Am. 2016;43:247-60.

24. Onasanya O, Iyer G, Lucas E, Lin D, Singh S, Alexander GC. Association between exogenous testosterone and cardiovascular events: an overview of systematic reviews. Lancet Diabetes Endocrinol. 2016;4:943-56.

25. Alexander GC, lyer G, Lucas E, Lin D, Singh S. Cardiovascular Risks of Exogenous Testosterone Use Among Men: A Systematic Review and Meta-Analysis. Am J Med. 2017;130:293-305.

26. Bandari J, Ayyash OM, Emery SL, Wessel CB, Davies BJ. Marketing and Testosterone Treatment in the USA: A Systematic Review. Eur Urol Focus. 2017;S24054569(17)30256-0.

27. Kicinski M, Springate DA, Kontopantelis E. Publication bias in meta-analyses from the Cochrane Database of Systematic Reviews. Stat Med. 2015;34:2781-93.

28. Kicinski M. Publication bias in recent meta-analyses. PLoS One. 2013;8:e81823. Erratum in: PLoS One. 2014;9(1).

29. Morgentaler A, Traish AM. Shifting the paradigm of testosterone and prostate cancer: the saturation model and the limits of androgen-dependent growth. Eur Urol. 2009;55:310-20.

30. Traish AM, Williams DF, Hoffman ND, Wotiz HH. Validation of the exchange assay for the measurement of androgen receptors in human and dog prostates. Prog Clin Biol Res. 1988;262:145-60.
31. Rastrelli G, Corona G, Vignozzi L, Maseroli E, Silverii A, Monami M, et al. Serum PSA as a predictor of testosterone deficiency. J Sex Med. 2013;10:2518-28.

32. Loeb S, Folkvaljon Y, Damber JE, Alukal J, Lambe M, Stattin P. Testosterone Replacement Therapy and Risk of Favorable and Aggressive Prostate Cancer. J Clin Oncol. 2017;35:1430-6.

33. Muller RL, Gerber L, Moreira DM, Andriole G, CastroSantamaria R, Freedland SJ. Serum testosterone and dihydrotestosterone and prostate cancer risk in the placebo arm of the Reduction by Dutasteride of Prostate Cancer Events trial. Eur Urol. 2012;62:757-64.

34. Hoffman MA, DeWolf WC, Morgentaler A. Is Iow serum free testosterone a marker for high grade prostate cancer? J Urol. 2000;163:824-7.

35. Yamamoto S, Yonese J, Kawakami S, Ohkubo Y, Tatokoro M, Komai $Y$, et al. Preoperative serum testosterone level as an independent predictor of treatment failure following radical prostatectomy. Eur Urol. 2007;52:696-701.

36. Salonia A, Gallina A, Briganti A, Suardi N, Capitanio U, Abdollah F, et al. Circulating estradiol, but not testosterone, is a significant predictor of highgrade prostate cancer in patients undergoing radical prostatectomy. Cancer. 2011;117:5029-38.

37. Teloken C, Da Ros CT, Caraver F, Weber FA, Cavalheiro AP, Graziottin TM. Low serum testosterone levels are associated with positive surgical margins in radical retropubic prostatectomy: hypogonadism represents bad prognosis in prostate cancer. J Urol. 2005;174:2178-80.

38. Bul M, Zhu X, Valdagni R, Pickles T, Kakehi Y, Rannikko A, et al. Active surveillance for low-risk prostate cancer worldwide: the PRIAS study. Eur Urol. 2013;63:597603.

39. Pastuszak AW, Rodriguez KM, Nguyen TM, Khera M. Testosterone therapy and prostate cancer. Transl Androl Urol. 2016;5:909-20.

40. Khera M. Androgens and erectile function: a case for early androgen use in postprostatectomy hypogonadal men. J Sex Med. 2009;6 (Suppl 3):234-8.

41. Kaufman JM, Graydon RJ. Androgen replacement after curative radical prostatectomy for prostate cancer in hypogonadal men. J Urol. 2004;172:920-2.

42. Agarwal PK, Oefelein MG. Testosterone replacement therapy after primary treatment for prostate cancer. J Urol. 2005;173:533-6.

43. Khera M, Grober ED, Najari B, Colen JS, Mohamed 0, Lamb DJ, et al. Testosterone replacement therapy following radical prostatectomy. J Sex Med. 2009:6:1165-70.

44. Pastuszak AW, Pearlman AM, Lai WS, Godoy G, Sathyamoorthy K, Liu JS, et al. Testosterone replacement therapy in patients with prostate cancer after radical prostatectomy. J Urol. 2013;190:639-44. 
45. Kaplan AL, Trinh QD, Sun M, Carter SC, Nguyen PL, Shih YT, Marks LS, Hu JC. Testosterone replacement therapy following the diagnosis of prostate cancer: outcomes and utilization trends. J Sex Med. 2014;11:1063-70.
46. Ory J, Flannigan R, Lundeen C, Huang JG, Pommerville P, Goldenberg SL. Testosterone Therapy in Patients with Treated and Untreated Prostate Cancer: Impact on Oncologic Outcomes. J Urol. 2016;196:1082-9.

\section{Marcelo Langer Wroclawski, MD}

Hospital Israelita Albert Einstein, São Paulo, Brasil Av. Albert Einstein, 627/701 Morumbi, São Paulo, SP, 05652-900, Brasil E-mail: urologia.marcelo@gmail.com 